\title{
DO TRANSPORTED NEONATES ENJOY A WARM TRIP?
}

\author{
L. Abbott $^{1}$, H. Hysted ${ }^{2}$, H. Steve ${ }^{2}$ \\ ${ }^{1}$ Jessop Wing, Neonatal Unit, Royal Hallamshire Hospital, ${ }^{2}$ Embrace Transport Service, Sheffield Children's \\ Hospital, Sheffield, UK
}

Thermal stability of Neonates requires active management and remains a significant challenge during transport due to less reliable equipment, limited range of options and environmental exposure.

This study aimed to compare axillary with incubator sensor temperatures and analyse temperature variation throughout the transport process related to a mortality risk score.

Prospective analysis of 103 neonatal transfers was undertaken at first look, pre-departure and arrival phases of transport between April and July 2010. Mortality risk was calculated using the validated transport TRIPS score. Data was calculated as means \pm SEM and compared using 1 sample 2-tailed t-tests.

Incubator sensor temperatures were not clinically different from axillary temperatures (mean $36.8 \pm 0.05$ vs $36.4 \pm 0.04)$. There were no significant differences between axillary temperatures during first look, predeparture $(\mathrm{P}=0.37)$ and arrival transport phases (mean $36.9 \pm 0.04$ vs $37.0 \pm 0.04)$. TRIPS scores showed no significant variation throughout the transport process. Only 3 neonates showed worse mortality risk due to temperature change during transport; however all of these had poor TRIPS scores secondary to multisystem problems.

Transport Incubator sensor temperatures are as reliable as axilla, but clinical judgement must be used if erroneous results suspected. The regional transport team retrieves, transports and hands over optimal temperature neonates. A small number of babies have suboptimal temperatures - likely to be as a result of clinical state rather than sub-optimal management. For ongoing service evaluation it is recommended to complete an audit once per year using TRIPS data and incubator sensor temperatures over winter. 